\title{
Hypoxaemia in wheezy infants after bronchodilator treatment
}

\author{
A PRENDIVILlE, A ROSE, D L MAXWELL, AND M SILVERMAN \\ Department of Paediatrics and Neonatal Medicine, and Division of Respiratory Medicine, Royal \\ Postgraduate Medical School, London
}

SUMMARY The response of the bronchi to nebulised salbutamol was measured in five recurrently wheezy infants. Changes in oxygenation (measured by pulse oximeter and transcutaneous $\mathrm{PO}_{2}$ electrodes) and carbon dioxide (measured by transcutaneous $\mathrm{PCO}_{2}$ electrode) were recorded at the same time. Neither nebulised saline nor salbutamol caused any changes in the measurements of airway function. A significant drop in mean oxygen saturation of $2 \%$ and of transcutaneous oxygen tension of $1.3 \mathrm{kPa}$ occurred after nebulised salbutamol. No significant change occurred in measurements of transcutaneous carbon dioxide tension, nor was there any significant change in any of these measurements after $2.5 \mathrm{ml}$ of nebulised saline had been given as a control. These results suggest that nebulised salbutamol may cause significant hypoxaemia, in wheezy infants probably by inducing ventilation/perfusion disturbance.

Nebulised selective $\beta_{2}$-adrenoceptor agonists are still used in the treatment of wheezing in infants in spite of the evidence that they may be ineffective..$^{1-3}$ Recently they have been shown to cause deterioration in peripheral airways function in this age group. ${ }^{4}$ Because the techniques used for measuring peripheral airway function in wheezy infants are new, ${ }^{67}$ it may be that any deterioration noted was artefactual.

In adults and older asthmatic children transient but significant hypoxaemia after treatment with selective $\beta_{2}$-adrenoceptor agonists has been reported despite improvement in airway patency. ${ }^{8-10}$ This may be the result of a disturbance in ventilation/ perfusion balance brought about by pulmonary vasodilatation. If a similar imbalance occurs in the infant lung, without bronchodilation severe hypoxaemia could result.

We assessed the changes in airway function and blood gas measurements after giving nebulised salbutamol to wheezy infants and compared them with a group given nebulised physiological saline.

\section{Patients and methods}

Five recurrently wheezy infants (mean age $10 \cdot 4$ months, range 6-15) were studied. They were sufficiently disturbed by wheeze to justify assessment with a view to nebuliser treatment at home.
All were wheezy at the time of testing. The reproducibility of the response to salbutamol was assessed two weeks later in four of the infants. The fifth infant did not have a repeat study because he developed severe bronchoconstriction after the initial treatment with salbutamol.

Sedation with chloral hydrate $(100 \mathrm{mg} / \mathrm{kg}$ orally) was given 30 minutes before each test. No infant had received any bronchodilator within 24 hours of the test. Ethical committee approval and parental consent were obtained for all studies.

PROCEDURE FOR SALBUTAMOL CHALLENGE

When asleep the infant was placed in a whole body plethysmograph, and baseline measurements of thoracic gas volume and inspiratory airway resistance were made. ${ }^{11}$ From these, their multiple specific airway resistance was calculated. Partial expiratory flow volume curves were then calculated by suddenly inflating a snugly fitting thoracoabdominal jacket at the end of a tidal inspiration, thus causing forced expiration. ${ }^{6} /$ From the flow signal measured through the face mask by the screen pneumotachograph and its integral (volume), a partial expiratory flow volume curve was constructed, and the maximum flow at a lung volume corresponding to functional residual capacity was computed. Six to eight of these manoeuvres were carried out to obtain a mean baseline value for the 
maximum flow at functional residual capacity ( $\dot{V} \operatorname{maxFRC})$. Reference values for airway resistance and $\dot{V}$ maxFRC were obtained from previously reported data. ${ }^{12} 13$

The face mask was removed and $2.5 \mathrm{ml}$ physiological saline at room temperature was given through a Turret nebuliser (Medic Aid) driven by compressed air at $61 /$ minute; nebuliser output was directed over the nose and mouth of the sleeping infant, and the nebulisation time was about five minutes. A further set of partial expiratory flow volume curves was then obtained after replacing the face mask and waiting for the baby to settle for five minutes.

After a 20 minute interval $2.5 \mathrm{mg}$ of preservative free salbutamol sulphate in $2.5 \mathrm{ml}$ physiological saline (one Ventolin Nebule) was given by jet nebuliser as described above and further sets of flow volume curves obtained 20 minutes later.

\section{RECORDINGS}

Transcutaneous $\mathrm{PO}_{2}\left(\mathrm{PtcO}_{2}\right)$ was monitored using a transcutaneous electrode (Kontron Cutan 820) heated to $44^{\circ} \mathrm{C}$ and placed on the lower leg after calibration in air. Transcutaneous $\mathrm{PCO}_{2}\left(\mathrm{PtcCO}_{2}\right)$ was monitored using a transcutaneous electrode (Radiometer TCM 20) heated to $43^{\circ} \mathrm{C}$ and placed on the lower leg after calibration in $10 \%$ carbon dioxide. Readings of $\mathrm{PtcO}_{2}$ and $\mathrm{PtcCO}_{2}$ were taken after a stabilisation period of 15 to 20 minutes. A pulse oximeter (Ohmeda Biox 3700) was used to measure arterial oxygen saturation $\left(\mathrm{SaO}_{2}\right)$ and heart rate. Data were recorded only when the pulse signal was satisfactory.

Values of $\mathrm{SaO}_{2}, \mathrm{PtcO}_{2}, \mathrm{PtcCO}_{2}$ and heart rate were recorded in the five minutes before and throughout the challenge procedures, and for 20 minutes after the saline and salbutamol had been given. For statistical purposes, comparisons were made between the mean values during the five minute interval before nebulisation and those measured during 0-5 and 15-20 minutes after nebulisation. The paired $t$ test was used to test the significance of differences in results after treatment with salbutamol and with saline.

\section{Results}

The results for the two study days were similar, with no significant differences between days. Where two sets of data were collected, mean values were used giving one set of results for each of the five patients.

Baseline measurements of lung function indicated that there was definite airway obstruction; the mean (SD) value of specific airway resistance was 249 (106) $\%$ of the reference value ${ }^{12}$ and the VंmaxFRC was $24(8.4) \%$ of the reference value. ${ }^{13}$ Baseline values of $\mathrm{PtcO}_{2}$, and $\mathrm{PtcCO}_{2}$ before giving the saline (table) reflect the errors inherent in methods of
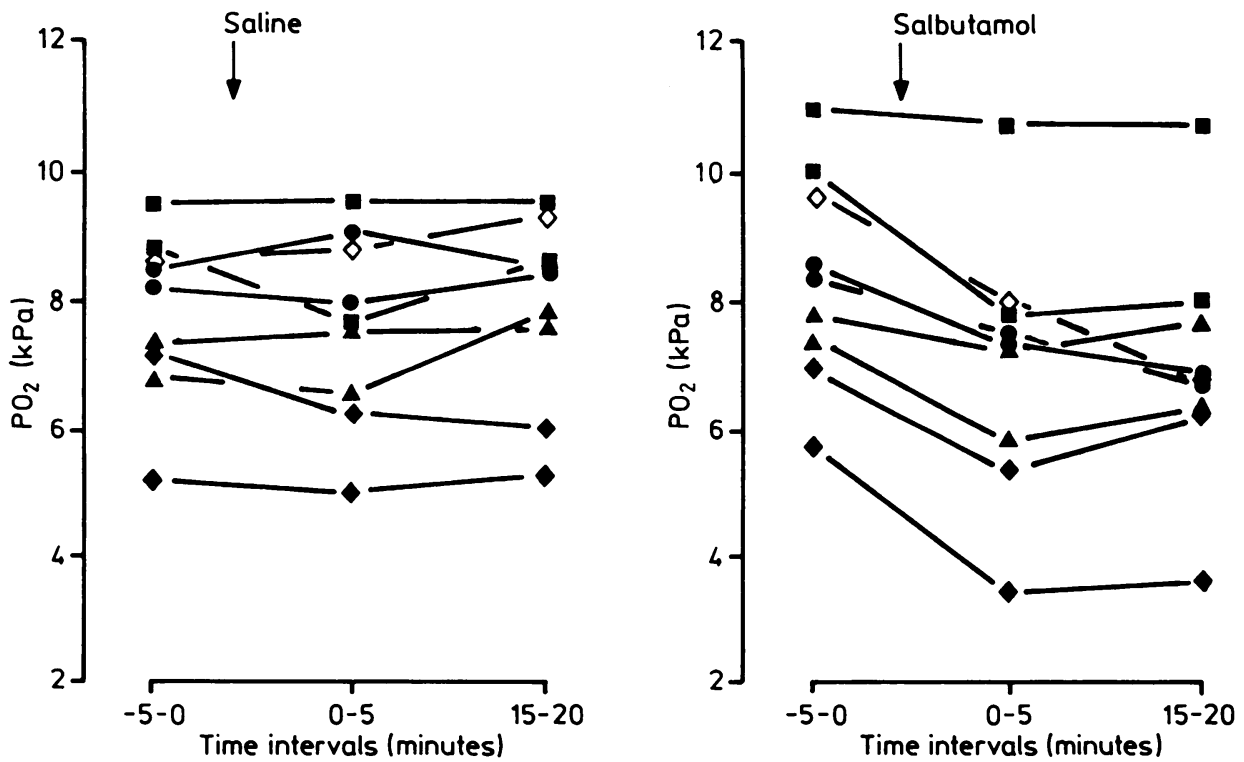

Figure Changes in peripheral transcutaneous $\mathrm{O}_{2}$ before and after nebulised saline and salbutamol. Each point represents mean value over each five minute interval for four infants studied on two occasions each (closed symbols) and one infant studied only once (open symbols). 
Table Mean (SD) values of $\dot{V}$ maxFRC, heart rate, oxygen saturation, transcutaneous $\mathrm{PO}_{2}$, and transcutaneous $\mathrm{PCO}_{2}$ in the five minute intervals before and after nebulised saline and salbutamol

\begin{tabular}{|c|c|c|c|c|c|c|c|c|}
\hline & \multicolumn{4}{|c|}{ Nebulised saline } & \multicolumn{4}{|c|}{ Nebulised salbutamol } \\
\hline & $\begin{array}{l}\text { Before } \\
\text { Mean }\end{array}$ & $(S D)$ & $\begin{array}{l}\text { After } \\
\text { Mean }\end{array}$ & $(S D)$ & $\begin{array}{l}\text { Before } \\
\text { Mean }\end{array}$ & $(S D)$ & $\begin{array}{l}\text { After } \\
\text { Mean }\end{array}$ & $(S D)$ \\
\hline$\dot{\mathrm{V}} \operatorname{maxFRC}(\mathrm{ml} / \mathrm{sec})$ & 24 & $(8 \cdot 4)$ & 25 & $(6 \cdot 5)$ & 26 & $(6 \cdot 5)$ & 25 & $(11 \cdot 1)$ \\
\hline Heart rate & 133 & (15) & 132 & (14) & 135 & (17) & 151 & $(14)^{*}$ \\
\hline Oxygen saturation (\%) & 86 & $(5 \cdot 6)$ & 86 & $(5.4)$ & 87 & $(6 \cdot 7)$ & 85 & $(7 \cdot 0)^{*}$ \\
\hline Transcutaneous $\mathrm{O}_{2}(\mathrm{kPa})$ & $7 \cdot 8$ & $(1 \cdot 1)$ & $7 \cdot 7$ & $(1 \cdot 2)$ & 8.5 & $(1 \cdot 5)$ & $7 \cdot 2$ & $(1.6) \dagger$ \\
\hline Transcutaneous $\mathrm{CO}_{2}(\mathrm{kPa})$ & 58 & $(4 \cdot 1)$ & 57 & $(4 \cdot 1)$ & 56 & $(3 \cdot 4)$ & 55 & $(3.9)$ \\
\hline
\end{tabular}

Before and after salbutamol: ${ }^{*} \mathrm{p}<0 \cdot 01 \dagger \mathrm{p}<0 \cdot 001$.

transcutaneous measurement. The mean value of $\mathrm{SaO}_{2}$ was significantly lower than normal in these supine, sedated, wheezy infants.

Significant falls in both $\mathrm{PtcO}_{2}(\mathrm{p}<0.001$; figure $)$ and $\mathrm{SaO}_{2}(\mathrm{p}<0.01)$ occurred within five minutes of giving of nebulised salbutamol, but not after saline (table). The lowest values of $\mathrm{PtcO}_{2}(6.6 \mathrm{kPa})$ and $\mathrm{SaO}_{2}(84 \%)$ occurred at a mean time of 11 minutes after the end of nebulisation. Twenty minutes after the end of nebulisation the mean value for $\mathrm{PtcO}_{2}$ of $7 \cdot 1 \mathrm{kPa}$ was still significantly lower than the mean value of $8.5 \mathrm{kPa}$ before salbutamol $(\mathrm{p}<0.01)$, although the $\mathrm{SaO}_{2}$ had returned to the baseline value.

There were small changes in $\mathrm{PtcCO}_{2}$ measurements. The small decline after salbutamol had been given was not significant (table). Mean heart rate increased significantly after salbutamol was started, the increase persisting for at least 20 minutes after nebulisation had stopped. There was no significant change in heart rate with nebulised saline.

\section{Discussion}

We found a significant deterioration in oxygenation in wheezy infants after they had been given salbutamol. These changes were similar to those reported in older asthmatic children and adults. ${ }^{8-10}$ There was a small decline in $\mathrm{PtcCO}_{2}$ in conjunction with the hypoxaemia. In adults these changes probably reflect an increase in ventilation/perfusion disturbance secondary to pulmonary vasodilatation. There were certainly cardiovascular effects in our infants, shown by tachycardia. Ventilation/perfusion disturbances may be more likely to occur in infants, because babies do not have any of the ameliorating effects of bronchodilatation in response to salbuta$\mathrm{mol}$, in spite of the fact that they do have functional airway $\beta$-adrenoceptors. ${ }^{14}$ Airway obstruction may actually increase after bronchodilation, contributing to hypoxaemia. ${ }^{4}$
Jet nebulisation causes a gradual increase in the osmolality of the nebulisate. This is more likely to occur with long nebulisation times and small starting volumes,${ }^{15}$ and occurs with both the nebulised saline and with salbutamol. ${ }^{15} 16$ This increase in osmolality could explain the adverse effects on airway function in wheezy infants, although these effects seem to be short lived. ${ }^{17}$

In contrast both the hypoxic effects of salbutamol and the decline in forced expiratory flow rates were still present 20 minutes after nebulisation, suggesting a persistent pharmacological effect. ${ }^{4}$

The validity of our results may be questioned because these infants were studied while asleep under sedation with chloral hydrate. Although oxygen consumption and production of carbon dioxide have been shown to be slightly higher in infants under sedation with chloral hydrate, this type of sedation produces steady oxygen consumption, endogenous carbon dioxide production, and end tidal $\mathrm{PCO}_{2}$, and does not affect carbon dioxide chemoreceptor responsiveness, thus providing stable baseline readings from which to calculate changes in oxygen and carbon dioxide concentrations. ${ }^{18}$ Face mask application causes changes in respiratory patterns in infancy. ${ }^{19}$ All recordings of $\mathrm{SaO}_{2}, \mathrm{PtcO}_{2}$, and $\mathrm{PtcCO}_{2}$ were taken after removal of the face mask, allowing for a period of stabilisation.

Transcutaneous measurements provide indirect values for $\mathrm{PaO}_{2}$ and $\mathrm{PaCO}_{2}$, but these values do bear a close and proportional correlation with the true values. ${ }^{20-23}$ Changes in transcutaneous values should therefore indicate arterial changes as long as the coefficient of proportionality remains unchanged. We cannot be sure that nebulised salbutamol did not change cutaneous blood flow, but the relative stability of $\mathrm{PCO}_{2}$ readings argues against this. In addition, the parallel decline in $\mathrm{SaO}_{2}$ and $\mathrm{PtcO}_{2}$ reinforces the validity of the transcutaneous measurements. 
This study has important clinical implications. As well as showing a paradoxical effect on airway function in wheezy infants, ${ }^{4}$ we have shown that nebulised bronchodilators may have an adverse effect on arterial oxygenation. The effect persisted for at least 20 minutes. It may be that in the presence of more severe airway obstruction and hypoxaemia a more severe adverse reaction to nebulised bronchodilator could occur: this would require urgent treatment with oxygen.

We are grateful to Mr N Levy and Mr J Messeguer for technical help. The work was supported by the Asthma Research Council. Allen \& Hanburys Ltd, and Hammersmith and Queen Charlotte's Special Health Authority.

\section{References}

1 Radford M. Effect of salbutamol in infants with wheezy bronchitis. Arch Dis Child 1975;50:535-8.

2 Rutter N. Milner AD. Hiller EJ. Effect of bronchodilators on respiratory resistance in infants and young children with bronchiolitis and wheczy bronchitis. Arch Dis Child 1975;50:719-22.

${ }^{3}$ Stokes GM, Milner AD, Hodges IGC, Henry RL, Elphick MC. Nebulised therapy in acute severe bronchiolitis in infancy. Arch Dis Child 1983;58:279-82.

${ }^{4}$ Prendiville A. Green S. Silverman M. Paradoxical response to nebulised salbutamol in wheezy infants, assessed by partial expiratory flow volume curves. Thorax 1987;42:86-91.

5 Maayan C, Itzhaki T, Baryishay E, Gross S. Tal A. Godfrey S The functional response of infants with persistent wheezing to nebulised beclomethasone dipropionate. Pediatr Pulmonol 1986;2:9-14.

${ }^{6}$ Taussig LM, Landau LI. Godfrey S, Arad I. Determinants of forced expiratory flow in newborn infants. $J$ Appl Physiol 1982:53:1220-7.

${ }^{7}$ Silverman M, Prendiville A. Green S. Partial expiratory flow-volume curves in infancy: technical aspects. Bull Eur Physiopathol Respir 1986;22:257-62.

$\checkmark$ Thiessen B, Pedersen OF. A double blind cross over study of maximal expiratory flows and arterial blood gas tensions in normals, asthmatics and bronchitics after salbutamol and ipratropium. Scandinavian Journal of Respiratory Diseases 1979;103(suppl): 170-2.
"Tal A. Pasterkamp H, Leahy F. Arterial oxygen desaturation following salbutamol inhalation in acute asthma. Chest 1986:6:868-9.

1" Murray AB. Hardwick DF. Pirie GE. Frazer BM. The effects of pressurised isopropterenol and salbutamol in asthmatic children. Pediatrics 1974:54:746-56.

1 Stocks J, Thomson A. Silverman M. The numerical analysis of pressure-tlow curves in infancy. Pediatr Pulmonol 1985:1:19-26.

12 Stocks J. The functional growth of the lung during the first year of life. Early Hum Dev 1977:1:285-309.

${ }^{13}$ Beardsmore CS, Silverman M, Godfrey S. Maximum expiratory flow-volume curves in infancy. Bull Eur Physiopathol Respir (In press.)

it Prendiville A. Green S. Silverman M. Airway responsiveness in wheezy infants; Evidence for functional beta adrenergic receptors. Thorax 1987:42:10(1)-4.

15 Wood JA. Wilson RSE, Bray C. Changes in salbutamol concentration of a jet nebuliser. Br J Dis Chest 1986:80:164-9.

${ }^{16}$ Ferron GA, Kerrebijn KF. Webber J. Propertics of acrosols produced with three nebulisers. Am Rev Respir Dis 1976;114:899-908

17 O'Callaghan C. Milner AD. Swarbrick NA. Paradoxical deterioration in lung function after nebulised salbutamol in wheezy infants. Lancet 1986:ii:1424-5.

${ }^{1 \times}$ Lees MH, Olsen G, McGillard KL, et al. Chloral hydrate and the carbon dioxide chemoreceptor response: a study of puppies and infants. Pediatrics 1982;70:447-50.

${ }^{19}$ Fleming PT, Levine MR. Goncalves A. Changes in respiratory pattern resulting from the use of a facemask to record respiration in newborn infants. Pediatr Res 1982;16:1031-4.

21 Monaco F. Nickerson BG. McQuitty JC. Continuous transcutaneous oxygen and carbon dioxide monitoring in the pediatric ICU. Crit Care Med 1982:10:765-6.

${ }^{21}$ Marsden D, Chiu MC, Paky F, Helms D. Transcutancous oxygen and carbon dioxide monitoring in intensive care. Arch Dis Child 1985;60:1158-61

22 Cheriyan G, Helms P. Paky F. Marsden D. Chiu MC. Transcutaneous estimation of arterial carbon dioxide in intensive care. Which electrode temperature? Arch Dis Child 1986:61:652-6.

23 Yahau T. Mindorff C. Levison $H$. The validity of the transcutaneous oxygen tension method in children with cardiorespiratory problems. Am Rev Respir Dis 1981;124:586-7.

Correspondence to Dr M Silverman. Department of Paeditrics and Neonatal Medicine. Hammersmith Hospital. London W12 0HS

Received 26 May 1987 